Ressourcen erspielen

DOI 10.1007/978-3-662-48648-1

ERRATUM

\title{
Erratum zu: Ressourcen erspielen
}

\author{
Ursula Stöhr
}

(C) Springer-Verlag Berlin Heidelberg 2016

Trotz sorgfältiger Erstellung unserer Bücher lassen sich Fehler nie ganz vermeiden.

Daher möchten wir auf Folgendes hinweisen:

Der Untertitel wurde nachträglich erweitert, er lautet nun:

Pflegen mit Freude

Seniorenspielbuch 2

Die Online-Version des aktualisierten Originalbuches können Sie unter http://dx.doi.org/10.1007/978-3-662-48648-1 finden 